\title{
The effects of increased heme oxygenase-1 on the lymphoproliferative response in dogs with visceral leishmaniasis
}

\section{Breno Fernando Martins de Almeida ${ }^{a}, *$, Kathlenn Liezbeth Oliveira Silva ${ }^{a}$, Vanessa Marim Chiku a ${ }^{a}$ Aline Aparecida Correa Leal ${ }^{a}$, Gabriela Lovizutto Venturin ${ }^{a}$, Luis Gustavo Narciso a , Maria Fernanda Cereijido Bersni Fink ${ }^{\mathrm{a}}$, Flavia de Rezende Eugênio ${ }^{\mathrm{b}}$, Paulo Sergio Patto dos Santos ${ }^{\mathrm{b}}$, Paulo Cesar Ciarlini ${ }^{\mathrm{b}}$, Valéria Marçal Felix de Lima ${ }^{a, b}$}

\author{
a Immunology Laboratory, São Paulo State University (Unesp), School of Veterinary Medicine, Rua Clovis Pestana 793, Araçatuba, São Paulo, CEP \\ 16050-680, Brazil \\ ${ }^{\mathrm{b}}$ Department of Animal Internal Medicine, Surgery and Reproduction, São Paulo State University (Unesp), School of Veterinary Medicine, Rua Clovis \\ Pestana 793, Araçatuba, São Paulo, CEP 16050-680, Brazil
}

\section{A R T I C L E I N F O}

\section{Article history:}

Received 19 September 2016

Received in revised form 5 December 2016

Accepted 27 December 2016

Available online 30 December 2016

\section{Keywords:}

HSP32

Leishmania infantum

Canine

Lymphoproliferation

\begin{abstract}
A B S T R A C T
Canine visceral leishmaniasis (CVL) is known to affect the cellular immunity of infected dogs, through impairing lymphoproliferation and microbicidal mechanisms. This study examined heme oxygenase- 1 (HO-1) and its metabolites, oxidative stress and IL-10 levels in CVL and investigated correlations between these parameters. Additionally, the effects of HO-1 inhibition on the lymphoproliferative response and cytokine production in lymph node cells (LNCs) from infected dogs were evaluated. Forty-four dogs, 24 controls and 20 dogs with CVL were selected. Plasma and splenic levels of HO-1, haptoglobin, soluble CD163 receptor, ferritin and IL-10 were determined using capture ELISA. The HO- 1 levels and relative gene expression in peripheral blood and bone marrow mononuclear cells were also determined. LNCs proliferation was evaluated with an HO-1 activator and with an HO-1 inhibitor, in the presence of the Leishmania infantum soluble antigen (SAgL), using flow cytometry. HO-1, IL-2, IFN-gamma and IL-10 were also determined in these cultures using capture ELISA. Infected dogs presented oxidative stress and increased HO-1 levels and relative gene expression, with correlation between oxidative stress and HO- 1 . The substances from heme metabolism and IL-10 were also elevated in the plasma and spleens of infected dogs. IL-10 and HO-1 levels were positively correlated with one another. Inhibition of HO-1 increased LNCs proliferation and decreased IL-10 and IL-2 production in the presence of SAgL. The increased HO-1 metabolism observed in CVL is probably associated with oxidative stress and increased IL-10, which could be one of the mechanisms responsible for inhibition of the lymphoproliferative response in sick dogs.
\end{abstract}

(c) 2016 Elsevier GmbH. All rights reserved.

Abbreviations: ALP, alkaline phosphatase; ALT, alanine aminotransferase; AST, aspartate aminotransferase; BMMC, bone marrow mononuclear cells; CBC, complete

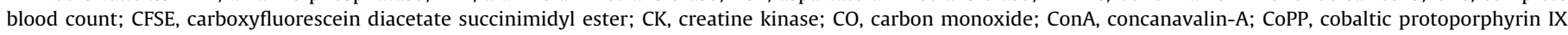

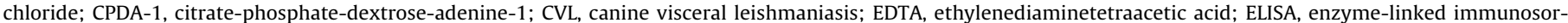

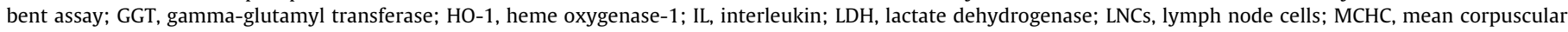

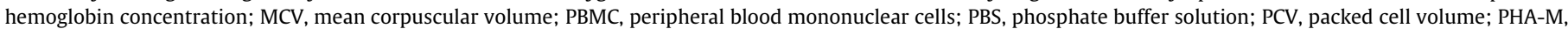

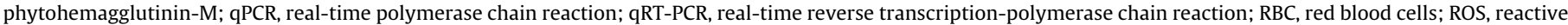

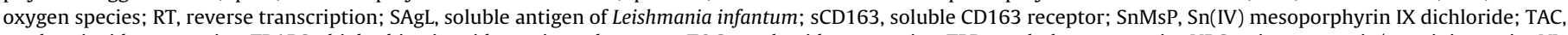

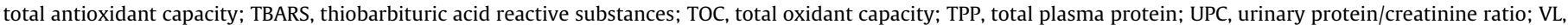
visceral leishmaniasis; WBC, white blood cells.

* Corresponding author.

E-mail addresses: bfmalmeida@yahoo.com.br, bfmalmeida@fio.edu.br (B.F.M.d. Almeida). 


\section{Introduction}

Visceral leishmaniasis (VL) is a parasitic zoonosis that is widely distributed throughout the world and is among the six most important tropical diseases according to the World Health Organization (WHO, 2015). Over recent years, increases in the incidence of VL have been reported in Brazil (Alvar et al., 2012). The increased incidence of human cases appears to be associated with increases in canine infections (Coura-Vital et al., 2011; Nunes et al., 2010) because dogs are the primary source of this disease in urban areas (Gramiccia and Gradoni, 2005).

This dog-susceptible disease is characterized by skin lesions, generalized lymphadenopathy, progressive weight loss with muscle atrophy and weakness, exercise intolerance, decreased appetite, lethargy, splenomegaly, polyuria and polydipsia, eye lesions, epistaxis, onychogryphosis, vomiting and diarrhea (Solano-Gallego et al., 2009).

It has been accepted that susceptibility is associated with an exacerbated humoral immune response (Th2) and a reduced cellular immune response (Th1) (Alvar et al., 2004; Baneth et al., 2008). Increased production of IL-10, a major Th2 cytokine, is associated with progression of the canine infection (Boggiatto et al., 2010), while higher expression of IFN-gamma, a Th1 cytokine, is correlated with a lower blood parasite load (Solano-Gallego et al., 2016).

Recently, it has been suggested that oxidative stress in infected dogs presenting clinical signs of canine visceral leishmaniasis (CVL) is associated with increased production of reactive oxygen species (ROS), which may be a critical mechanism of the pathogenesis of this disease (Almeida et al., 2013b; Bildik et al., 2004; Heidarpour et al., 2012). This increased ROS production has been demonstrated in human macrophages (Luz et al., 2012) and canine neutrophils (Almeida et al., 2013a,b).

The mechanisms associated with CVL susceptibility are not well-understood. Information regarding CVL disease pathogenicity is fundamental for future treatments for dogs. Involvement of heme oxygenase-1 (HO-1) in human VL susceptibility has been reported (Das et al., 2013; Luz et al., 2012). HO-1 is responsible for degrading the heme in hemoglobin into iron, carbon monoxide and biliverdin, which is rapidly converted into bilirubin (Tenhunen et al., 1969). Under physiological conditions, hemoglobin from erythrocyte destruction binds with haptoglobin and this complex is then internalized by macrophages via the CD163 receptor. Inside the macrophage, heme is metabolized by HO-1 and iron stimulates ferritin production (Kristiansen et al., 2001).

Human patients with clinical VL have been found to present increased HO-1 levels, which then decreased after disease treatment. This clinical finding demonstrates the involvement of HO-1 in VL susceptibility (Das et al., 2013; Luz et al., 2012). Furthermore, both the lipophosphoglycan and promastigote parasite forms of Leishmania spp. are responsible for increasing HO-1 expression in macrophages, resulting in the persistence of the infection in humans (Luz et al., 2012). Because heme is necessary for complete NADPH oxidase activation, the underlying mechanism causing persistence of this macrophage infection is possibly associated with heme degradation caused by $\mathrm{HO}-1$, which prevents complete activation of NADPH oxidase. Thus, ROS production by infected macrophages is impaired, and this allows the parasite to survive inside the host cell (Pham et al., 2005).

HO-1 also presents immunoregulatory functions, mainly those associated with lymphocytes, by inhibiting activation and proliferation of T lymphocytes and stimulating apoptosis in these cells (Pae et al., 2004). To date, the involvement of HO-1 in the lymphoproliferative response of dogs with CVL has not been studied. However, it is known that infected dogs with clinical signs of CVL exhibit low lymphocyte proliferative responses (Pinelli et al., 1994). The mechanisms involved in this impaired cell response may be related to increased T lymphocyte apoptosis (Chiku et al., 2016; Lima et al., 2012; Perosso et al., 2014). Therefore, gaining an understanding of the mechanisms that improve the lymphoproliferative response in sick dogs is critical for development of treatments and elimination of this parasite in dogs.

For the present study, it was assumed that HO- 1 production is activated under stress conditions, that oxidative stress occurs in CVL and that anemia is a common finding in relation to this condition. Hence, this study aimed to evaluate HO-1 levels and relative gene expression, along with $\mathrm{HO}-1$ metabolites, in infected dogs and to determine the correlations between HO-1, oxidative stress markers, IL-10 levels and parasite load. Additionally, we evaluated the regulatory role of $\mathrm{HO}-1$ relating to the antigen-specific proliferative response of lymph node cells from infected dogs and determined the effects of HO-1 activation and inhibition on the lymphoproliferative response and on IL-10, IL-2 and IFN-gamma production.

\section{Material and methods}

\subsection{Ethics approval}

This study was approved by the Ethics Committee for Animal Experimental Research (Comitê de Ética em Pesquisa Experimental Animal, COBEA) and the Ethics Committee for Animal Use (Comitê de Ética no Uso Animal, CEUA) of the School of Veterinary Medicine (Faculdade de Medicina Veterinária, FMVA) at the Araçatuba Campus of São Paulo State University (Universidade Estadual Paulista "Júlio de Mesquita Filho", Unesp), under procedural number FOA00532-2013. The participation of dogs in the control group was authorized by their keepers, who provided free and informed consent.

\subsection{Dog selection}

The control group consisted of 24 dogs of various breeds (10 males and 14 females; average age of $4 \pm 2$ years), which were recruited in the city of Araçatuba. The keepers of these dogs authorized their participation in the experiment. All the dogs were clinically healthy with normal physical examinations. These dogs presented normal hematological, biochemical and urinary profiles, and negative indirect ELISA reactions (Lima et al., 2003) for the $L$. infantum antigen obtained within the last three months before the experiment. There was no Leishmania DNA amplification (Perosso et al., 2014) in the spleen or bone marrow samples taken at the time of the experiment.

The infected group consisted of 20 dogs (10 males and 10 females; average age of $5 \pm 2$ years) of varying breeds that were naturally infected with Leishmania spp. These dogs were acquired from the Zoonosis Control Center of Araçatuba. General clinical examinations, complete blood counts, plasma biochemistry analyses and urinalyses were performed on these dogs to stage the disease in accordance with the LeishVet Consensus (Solano-Gallego et al., 2009). All the animals were reactive to total crude antigen of L. infantum through indirect ELISA (Lima et al., 2003) and presented positive Leishmania DNA amplification (Perosso et al., 2014) in spleen and bone marrow samples.

\subsection{Sample collection and laboratory analysis}

Prior to blood collection, the dogs were kept fasting for 8-12 h. Twenty-one milliliters of blood were extracted via jugular venipuncture; $20 \mathrm{~mL}$ was placed in heparinized tubes (BD Vacutainer $^{\circledR}$, Franklin Lakes, NJ, USA) and $1 \mathrm{~mL}$ of ethylenediaminetetraacetic acid (EDTA)-treated blood was used to determine the complete blood count (CBC). 
Heparinized blood was used to obtain plasma and peripheral blood mononuclear cells (PBMC) were isolated using a gradient density of $1.077 \mathrm{~g} / \mathrm{mL}$ (Histopaque- $1077^{\circledR}$, Sigma-Aldrich Co., St. Louis, USA), in accordance with the manufacturer's recommendations.

The CBC, plasma biochemistry, urinalysis and urinary protein/creatinine ratio (UPC) were determined using methods described previously (Almeida et al., 2013b).

Bone marrow obtained from the right iliac crest using a Jamshidi needle was placed with citrate-phosphate-dextrose-adenine-1 (CPDA-1) anticoagulant (JP Ind. Pharmaceutical, Ribeirão Preto, SP, Brazil) (four parts of bone marrow to one part of anticoagulant). Isolation of bone marrow mononuclear cells (BMMC) followed the same protocol as for PBMC.

Partial splenectomy was performed by means of surgical excision, following the protocol described by Lima et al. (2012).

\subsection{Oxidative stress markers}

Total antioxidant capacity (TAC) was determined colorimetrically using a reduction method involving the cation ABTS (2,2'-azino-bis-[3-ethylbenzothiazoline-6-sulfonic acid]), following methods published previously (Erel, 2004).

Total oxidant capacity (TOC) was determined colorimetrically using the xylenol orange method, following methods described previously (Erel, 2005).

Lipid peroxidation was determined using thiobarbituric acid reactive substances (TBARS) in an automated plate reader (Readwell Touch, Robonik Private, Ltd., Navi Mumbai, Maharashtra, India) at $545 \mathrm{~nm}$, in accordance with previously described methods (Hunter et al., 1985). Lipid peroxidation was obtained after sample absorbance interpolation using a standard curve, with concentrations ranging from 0 to $100 \mu \mathrm{mol}$ of malondialdehyde/L. All reagents were obtained from Sigma-Aldrich (Sigma-Aldrich Co., St. Louis, USA).

\subsection{Lymphoproliferation assay}

The lymphoproliferation assay was performed on 15 infected dogs using lymph node cells (LNCs). After each dog had been sacrificed, its right popliteal lymph node was removed and macerated to obtain LNCs $\left(50 \times 10^{6} / \mathrm{mL}\right.$ in RPMI 1640 medium without calf bovine serum). LNCs were stained with the dye carboxyfluorescein diacetate succinimidyl ester $(2.5 \mu \mathrm{M})$ (CFSE, CellTrace ${ }^{\mathrm{TM}}$ CFSE Cell Proliferation Kit, Invitrogen Molecular Probes, Eugene, OR, USA) for $10 \mathrm{~min}$ at $37^{\circ} \mathrm{C}$, in accordance with the manufacturer's recommendations and with the previously published protocol (Lyons and Parish, 1994).

Stained LNCs were cultured in sterile 24-well plates $\left(10 \times 10^{6} / \mathrm{mL}\right)$ in RPMI 1640 medium (Sigma-Aldrich Co., St. Louis, USA) alone (control) or with the HO-1 activator cobaltic protoporphyrin IX chloride $(50 \mu \mathrm{M})$ (CoPP), the HO-1 inhibitor $\mathrm{Sn}(\mathrm{IV})$ mesoporphyrin IX dichloride $(50 \mu \mathrm{M})$ (SnMsP) (Santa Cruz Biotechnology, Dallas, TX, USA) or $20 \mu \mathrm{g}$ of protein $/ \mathrm{mL}$ of soluble antigen from L. infantum (SAgL) (MHOM/BR/00/MERO2). Cultures of two combined treatments (CoPP + SAgL and SnMsP + SAgL) were also performed. The mitogens concanavalin-A (ConA, $5 \mathrm{mg} / \mathrm{mL}$ ) and phytohemagglutinin-M (PHA-M, $5 \mu \mathrm{L} / \mathrm{mL}$ ) were used as positive controls. CFSE-unmarked LNCs were used to verify CFSE staining.

LNCs were cultured for 6 days at $37^{\circ} \mathrm{C}$ and at $5 \% \mathrm{CO}_{2}$. Ten thousand events were acquired in a flow cytometer (BD C5 Accuri Flow Cytometer, Ann Arbor, MI, USA). The analysis was performed using BD Accuri C6 Software (v. 1.0.264.21, Ann Arbor, MI, USA). Cell populations with a size and complexity similar to those of the lymphocyte population were selected.
The assays were repeated in duplicate under the same conditions without CFSE staining. Supernatants were used to determine IL-2, IFN-gamma and IL-10 levels. Pellet cells were used to determine HO-1 levels and relative expression.

SAgL production was carried out using a protocol described previously (Scott et al., 1987) with the following modifications: $L$. infantum promastigotes $\left(10^{8} / \mathrm{mL}\right)$ in a protease inhibitor solution (Complete, EDTA-free, Roche, Indianapolis, IN, USA) were sonicated and the suspension was centrifuged at $20,000 \mathrm{~g}$ for $30 \mathrm{~min}$ at $4{ }^{\circ} \mathrm{C}$. The supernatant was removed and centrifuged again at 20,000 $\mathrm{g}$ for $4 \mathrm{~h}$ at $4{ }^{\circ} \mathrm{C}$. The supernatant from the second centrifugation was collected, dialyzed and sterilized, and its protein content was measured using the bicinchoninic acid method (BCA Protein Assay $\mathrm{Kit}^{\mathrm{TM}}$, Thermo Scientific, Rockford, IL, USA), in accordance with the manufacturer's recommendations, and was stored at $-80^{\circ} \mathrm{C}$ for later use.

\subsection{Substances in HO-1 metabolic pathway and interleukins}

Ferritin, sCD163 and haptoglobin levels were determined in 50$\mu \mathrm{L}$ samples of plasma or spleen homogenate that were prepared in accordance with methods described previously (Corrêa et al., 2007), using capture ELISA with canine-specific reagents (Novateinbio, Woburn, MA, USA) following the manufacturer's recommendations.

HO-1 levels were determined in $50 \mu \mathrm{L}$ of plasma, LNCs, PBMC or BMMC homogenate using capture ELISA with canine-specific reagents (Novateinbio, Woburn, MA, USA), following the manufacturer's recommendations. Homogenates were prepared using $5 \times 10^{6}$ cells resuspended in $120 \mu \mathrm{L}$ of $0.1 \mathrm{M}$ phosphate buffer solution (PBS, pH 7.2), following sonication $\left(2 \times 20 \mathrm{~s}, 5 \mathrm{~W}, 4^{\circ} \mathrm{C}\right)$. Further sample dilution was not necessary. The values were normalized using the protein levels that had been determined spectrophotometrically using the bicinchoninic acid method (BCA Protein Assay $\mathrm{Kit}^{\mathrm{TM}}$, Thermo Scientific, Rockford, IL, USA).

IL-2, IL-10 and IFN-gamma levels were determined using capture ELISA and commercial reagents (Canine IL-10 DuoSet, Canine IL-2 DuoSet and Canine IFN-gamma DuoSet; R\&D Systems, Minneapolis, MN, USA), in accordance with the manufacturer's recommendations.

Plasma-free heme was determined biochemically using a commercial reagent (QuantiChrom Heme ${ }^{\mathrm{TM}}$ Assay Kit Bioassay Systems, Hayward, CA, USA), following the manufacturer's instructions.

\subsection{HO-1 relative gene expression}

To evaluate the relative gene expression of HO-1 (Hmox1), RNA was extracted from $25 \mathrm{mg}$ of spleen tissue or from $5 \times 10^{6}$ cells from the proliferation assay, BMMC and PBMC that had been stored at $-80^{\circ} \mathrm{C}$, using commercial reagents (RNeasy ${ }^{\circledR}$ Mini Kit, Qiagen, Valencia, CA, USA), following the manufacturer's instructions. RNA eluted in nuclease-free water was quantified spectrophotometrically (NanoDrop ND-1000, Nano-Drop Technologies ${ }^{\circledR}$, Wilmington, DE, USA) with a $260 / 280$ absorbance ratio varying from 2.0 to 2.2. Samples were stored at $-80^{\circ} \mathrm{C}$ until use in the reverse transcription reaction.

Reverse transcription (RT) was performed using a commercial reagent (QuantiTect ${ }^{\circledR}$ Reverse Transcription Kit, Qiagen, Valencia, CA, USA), in accordance with the manufacturer's specifications, from $100 \mathrm{ng}$ of RNA from spleen samples and $300 \mathrm{ng}$ from LNCs, PBMC and BMMC, all at a final volume of $20 \mu \mathrm{L}$. To produce a standard curve, two samples of each experimental group from each tissue were randomly selected and RT was performed using $1 \mu \mathrm{g}$ of RNA. The samples from each tissue were then pooled. All the 
cDNA was stored at $-80^{\circ} \mathrm{C}$ and pooled cDNA was diluted (1:5) immediately before sample amplification.

The primers (Sigma-Aldrich Co., St. Louis, USA) for each gene are described in Table 1.

Real-time reverse transcription-polymerase chain reactions (qRT-PCR) were performed in a thermocycler (CFX96 ${ }^{\mathrm{TM}}$ Real-Time System, Bio-Rad, Hercules, CA, USA), using a commercial reagent (QuantiNovaTM SYBR ${ }^{\circledR}$ Green PCR Kit, Qiagen, Valencia, CA, USA) and $2 \mu \mathrm{L}$ of cDNA from the sample or a standard curve following the manufacturer's instructions.

In triplicate, the samples and standard curve were incubated at $95^{\circ} \mathrm{C}$ for 2 min and then subjected to 40 cycles of $95^{\circ} \mathrm{C}$ for $15 \mathrm{~s}$ and $60^{\circ} \mathrm{C}$ for $30 \mathrm{~s}$, followed by a dissociation curve. The efficiency values, correlation coefficients and slopes ranged from 97.4 to $101.7 \%$, $0.994-0.999$ and -3.386 to -3.283 , respectively. Nuclease-free water (Sigma-Aldrich Co., St. Louis, USA) was used as the negative control for the reaction.

HO- 1 relative gene expression was determined after interpolating the cycle threshold $(\mathrm{Ct})$ of the samples on the standard curve. The values were normalized using the geometric mean of the reference gene expression (beta-actin and HPRT-1) and are represented as the relative gene expression.

\subsection{Parasite load}

Parasite load was determined in infected dogs from $25 \mathrm{mg}$ of spleen and $200 \mu \mathrm{L}$ of bone marrow. The DNA extraction and quantification, along with the real-time polymerase chain reaction (qPCR), were performed as previously described (Perosso et al., 2014).

\subsection{Statistics}

Variables were tested for normality (Shapiro-Wilk test) and homoscedasticity (Bartlett test). Unpaired t or Mann-Whitney tests were then used to compare the controls and infected dogs. To assess the effects of treatment on the lymphoproliferative response, an analysis was performed using the Friedman test with Dunn's post-test after testing for normality. Correlations were determined using the Spearman correlation coefficient. Tests were performed using field-specific software (GraphPad Prism v.6.00 for Windows, GraphPad Software, La Jolla, CA, USA; www.graphpad.com). The results were considered to be statistically significant when $\mathrm{P}<0.05$.

\section{Results}

\subsection{Characterization of infected dogs}

According to the staging criteria proposed by the LeishVet Consensus (Solano-Gallego et al., 2009), the infected dogs were predominantly in the stage II (moderate) and stage III (severe) disease states. They presented clinical signs such as lymphadenomegaly, skin lesions (exfoliative and seborrheic dermatitis, ulcerations and onychogryphosis), anorexia, weight loss and epistaxis. The main laboratory findings in the dogs in these stages of CVL were mild non-regenerative normocytic and hypochromic anemia, hyperproteinemia due to hyperglobulinemia, hypoalbuminemia, normal biochemical renal function (creatinine $<1.4 \mathrm{mg} / \mathrm{dL}$ ) and marked proteinuria (UPC $>0.5$ for stage II and UPC $>1.0$ for stage III). The infected dogs also presented high levels of antibodies against total crude $L$. infantum antigen in the indirect ELISA reaction (Table 2).

Other hematological disorders in the dogs with CVL included basophilia and neutrophilia, with or without associated leukocytosis, lymphopenia and eosinopenia (Table 2). Regarding the biochemical profile, the infected dogs presented increased AST, CK
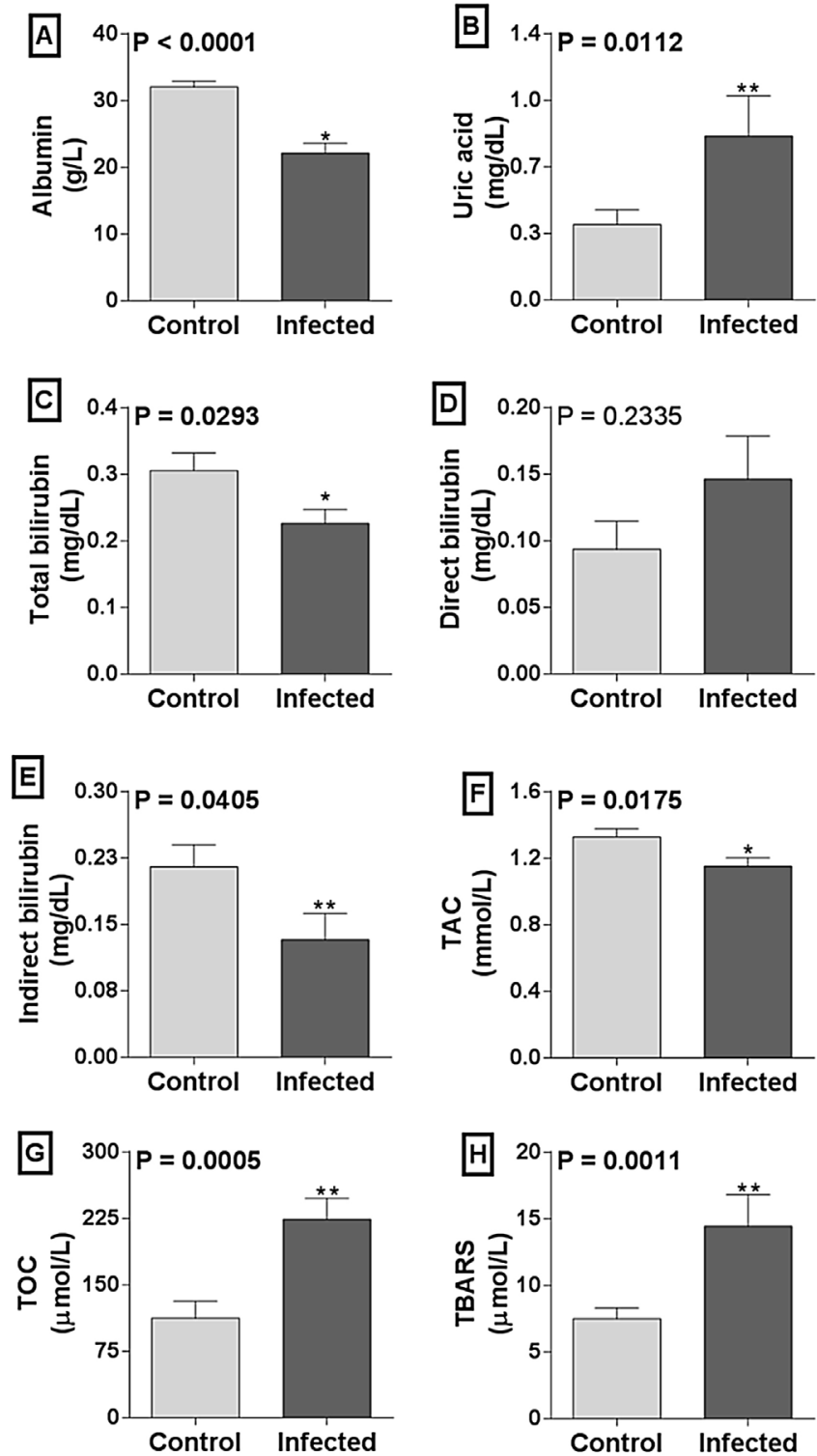

Fig. 1. Oxidative stress markers: albumin (A), uric acid (B) total bilirubin (C), direct bilirubin (D), indirect bilirubin (E), total antioxidant capacity (TAC, F), total oxidant capacity (TOC, G) and plasma lipid peroxidation measured using thiobarbituric acid reactive substances (TBARS, $\mathrm{H}$ ) in control dogs (Control, $\mathrm{n}=24$ ) and dogs with naturally occurring canine visceral leishmaniasis dogs (Infected, $n=20$ ). The graphs show the mean and standard error of the mean. Statistically significant differences are indicated by * (unpaired $t$-test) or ${ }^{* *}$ (Mann-Whitney test).

and LDH activity and decreased albumin, total and indirect bilirubin and calcium levels, compared with the uninfected dogs (Table 2).

The control dogs did not have any clinical or laboratory abnormalities (Table 2).

\subsection{Oxidative stress in CVL}

Confirming previous reports that oxidative stress occurs in CVL (Almeida et al., 2013b), we demonstrated that marked oxidative stress was present in the infected dogs. This can be seen through the reduced levels of antioxidants such as albumin (Fig. 1A), total bilirubin (Fig. 1C), indirect bilirubin (Fig. 1E) and TAC (Fig. 1F), as well as through the increased levels of oxidants measured via TOC (Fig. 1G) and lipid peroxidation (Fig. $1 \mathrm{H}$ ) in the infected dogs. Antioxidant uric acid (Fig. 1B) was elevated in dogs with CVL. There were no differences in the direct bilirubin content (Fig. 1D). 
Table 1

Sequences of forward $(\mathrm{F})$ and reverse $(\mathrm{R})$ primers for HO-1, beta-actin and HPRT-1 genes.

\begin{tabular}{|c|c|c|c|c|c|}
\hline Gene & Primer & Sequence $\left(5^{\prime} \rightarrow 3^{\prime}\right)$ & Product (bp) & GenBank access & Reference \\
\hline \multirow[t]{2}{*}{$\mathrm{HO}-1$} & $\mathrm{~F}$ & GCGTCGACTTCTTCACCTTC & 195 & AY563546.1 & Primer 3 Plus ${ }^{a}$ \\
\hline & $\mathrm{R}$ & GGTCCTCAGTGTCCTTGCTC & & & \\
\hline \multirow[t]{2}{*}{ Beta-actin } & $\mathrm{F}$ & CCAGCAAGGATGAAGATCAAG & 100 & AF021873 & Peters et al. (2007) \\
\hline & $\mathrm{R}$ & TCTGCTGGAAGGTGGACAG & & & \\
\hline \multirow[t]{2}{*}{ HPRT-1 } & $\mathrm{F}$ & CACTGGGAAAACAATGCAGA & 123 & AY283372 & Peters et al. (2007) \\
\hline & $\mathrm{R}$ & ACAAAGTCAGGTTTATAGCCAACA & & & \\
\hline
\end{tabular}

a Available from: www.primer3plus.com.

Table 2

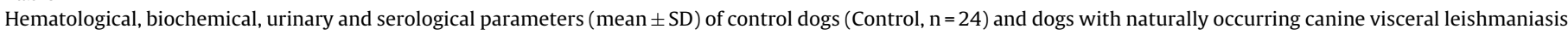
(Infected, $\mathrm{n}=20$ ).

\begin{tabular}{|c|c|c|c|c|}
\hline Parameter & Control & Infected & P-value & Reference range \\
\hline \multicolumn{5}{|l|}{ Hematological parameters } \\
\hline $\operatorname{PCV}(\%)$ & $46.70 \pm 5.60$ & $28.45 \pm 8.25^{*}$ & $<0.0001^{\ddagger}$ & $37-55$ \\
\hline $\operatorname{RBC}\left(10^{12} / \mathrm{L}\right)$ & $6.44 \pm 0.88$ & $4.44 \pm 1.24^{*}$ & $<0.0001$ & $5.5-8.5$ \\
\hline Hemoglobin (g/dL) & $15.13 \pm 2.07$ & $8.66 \pm 2.71^{*}$ & $<0.0001$ & $12-18$ \\
\hline $\operatorname{MCV}(\mathrm{fL})$ & $72.64 \pm 2.80$ & $63.85 \pm 4.52^{*}$ & $<0.0001$ & $60-77$ \\
\hline $\mathrm{MCHC}(\%)$ & $32.37 \pm 1.66$ & $30.29 \pm 1.55^{*}$ & $0.0001^{\dagger}$ & $32-36$ \\
\hline $\mathrm{WBC}\left(\times 10^{9} / \mathrm{L}\right)$ & $10.83 \pm 1.85$ & $15.00 \pm 9.92$ & $0.5995^{\dagger}$ & $6.0-17.0$ \\
\hline Neutrophils $\left(\times 10^{6} / \mathrm{L}\right)$ & $5973 \pm 1786$ & $12,740 \pm 9506^{*}$ & $\mathbf{0 . 0 0 2 2 ^ { \dagger }}$ & $3000-11,500$ \\
\hline Lymphocytes $\left(\times 10^{6} / \mathrm{L}\right)$ & $3177 \pm 916.3$ & $1305 \pm 1200^{*}$ & $<0.0001^{\dagger}$ & $1000-4800$ \\
\hline Monocytes $\left(\times 10^{6} / \mathrm{L}\right)$ & $608.4 \pm 435.2$ & $707.7 \pm 646.0$ & $0.7586^{\dagger}$ & $150-1350$ \\
\hline Eosinophils $\left(\times 10^{6} / \mathrm{L}\right)$ & $1029 \pm 870.5$ & $210.5 \pm 280.4^{*}$ & $<0.0001$ & $150-1250$ \\
\hline Basophils $\left(\times 10^{6} / \mathrm{L}\right)$ & $0 \pm 0$ & $57.0 \pm 92.59^{*}$ & $\mathbf{0 . 0 0 5 1}$ & Rare \\
\hline Platelet $\left(\times 10^{9} / \mathrm{L}\right)$ & $289.8 \pm 79.61$ & $237.6 \pm 119.9$ & $0.0953^{\ddagger}$ & $160-430$ \\
\hline $\mathrm{TPP}(\mathrm{g} / \mathrm{dL})$ & $7.01 \pm 0.98$ & $9.74 \pm 1.76^{*}$ & $<0.0001$ & $6.0-8.0$ \\
\hline \multicolumn{5}{|l|}{ Biochemical profile } \\
\hline Total protein $(\mathrm{g} / \mathrm{L})$ & $61.5 \pm 10.6$ & $86.7 \pm 11.9^{*}$ & $<0.0001$ & $54-71$ \\
\hline Albumin $(\mathrm{g} / \mathrm{L})$ & $32.06 \pm 3.98$ & $22.12 \pm 6.69^{*}$ & $<0.0001$ & $26-33$ \\
\hline Globulin (g/L) & $30.69 \pm 10.17$ & $63.51 \pm 10.18^{*}$ & $<0.0001^{\dagger}$ & $27-44$ \\
\hline $\operatorname{ALT}(\mathrm{IU} / \mathrm{L})$ & $34.05 \pm 10.48$ & $33.86 \pm 22.69$ & $0.2684^{\dagger}$ & $21-102$ \\
\hline AST (IU/L) & $23.63 \pm 5.59$ & $58.05 \pm 27.07^{*}$ & $<0.0001^{\dagger}$ & $23-66$ \\
\hline $\operatorname{ALP}(\mathrm{IU} / \mathrm{L})$ & $60.0 \pm 40.4$ & $86.7 \pm 75.5$ & $0.6285^{\dagger}$ & $20-156$ \\
\hline GGT $(\mathrm{IU} / \mathrm{L})$ & $3.15 \pm 1.0$ & $2.74 \pm 1.65$ & $0.0910^{\dagger}$ & $1.2-6.4$ \\
\hline Total bilirubin (mg/dL) & $0.30 \pm 0.12$ & $0.22 \pm 0.09^{*}$ & $\mathbf{0 . 0 2 9 3}^{\ddagger}$ & $0.1-0.5$ \\
\hline Direct bilirubin $(\mathrm{mg} / \mathrm{dL})$ & $0.09 \pm 0.10$ & $0.14 \pm 0.13$ & $0.1766^{\dagger}$ & $0.06-0.12$ \\
\hline Indirect bilirubin $(\mathrm{mg} / \mathrm{dL})$ & $0.21 \pm 0.12$ & $0.13 \pm 0.12^{*}$ & $\mathbf{0 . 0 4 0 5}^{\dagger}$ & $0.01-0.49$ \\
\hline Cholesterol $(\mathrm{mg} / \mathrm{dL})$ & $163.6 \pm 47.84$ & $183.5 \pm 64.56$ & $0.4732^{\dagger}$ & $135-270$ \\
\hline Triglycerides (mg/dL) & $62.1 \pm 23.7$ & $68.2 \pm 24.7$ & $0.3403^{\dagger}$ & $20-112$ \\
\hline Glucose $(\mathrm{mg} / \mathrm{dL})$ & $83.9 \pm 13.7$ & $90.2 \pm 16.0$ & $0.1689 \ddagger$ & $68-118$ \\
\hline Urea $(\mathrm{mg} / \mathrm{dL})$ & $35.6 \pm 9.5$ & $35.4 \pm 24.4$ & $0.0534^{\dagger}$ & $10-50$ \\
\hline Creatinine $(\mathrm{mg} / \mathrm{dL})$ & $0.99 \pm 0.18$ & $0.99 \pm 0.28$ & $0.1827^{\dagger}$ & $0.5-1.5$ \\
\hline CK $(\mathrm{IU} / \mathrm{L})$ & $96.96 \pm 59.55$ & $320.8 \pm 254.8^{*}$ & $<0.0001^{\dagger}$ & $1.5-28.4$ \\
\hline $\mathrm{LDH}(\mathrm{IU} / \mathrm{L})$ & $51.9 \pm 38.2$ & $155.0 \pm 110.2^{*}$ & $<0.0001^{\dagger}$ & $45-233$ \\
\hline Calcium $(\mathrm{mg} / \mathrm{dL})$ & $9.94 \pm 1.03$ & $8.92 \pm 0.62^{*}$ & $\mathbf{0 . 0 0 0 4} 4^{\ddagger}$ & $9.0-11.3$ \\
\hline Phosphorus (mg/dL) & $4.66 \pm 1.67$ & $5.56 \pm 1.69$ & $0.0746^{\dagger}$ & $2.6-6.2$ \\
\hline \multicolumn{5}{|l|}{ Urinary } \\
\hline Density & $1.043 \pm 0.01$ & $1.033 \pm 0.01$ & $0.1163^{\ddagger}$ & $>1.035$ \\
\hline UPC & $0.09 \pm 0.07$ & $1.66 \pm 1.84^{*}$ & $<0.0001^{\dagger}$ & $<0.5$ \\
\hline \multicolumn{5}{|l|}{ Indirect ELISA Serology } \\
\hline Optical density & $0.052 \pm 0.03$ & $0.935 \pm 0.211^{\ddagger}$ & $<0.0001^{\dagger}$ & $<0.270$ \\
\hline
\end{tabular}

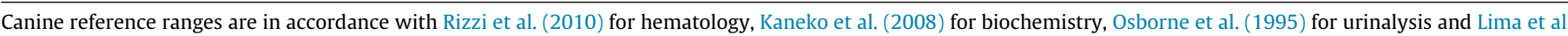
(2003) for indirect ELISA serology.

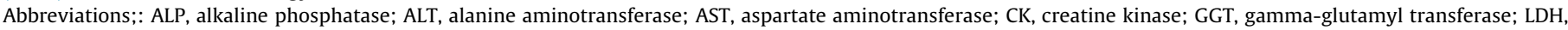

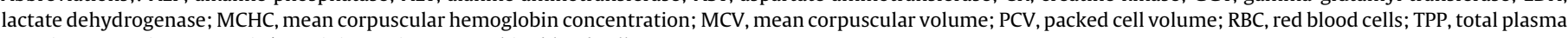
protein; UPC, urinary protein/creatinine ratio; WBC, white blood cells.

* Statistically significant difference using unpaired $t$-test $(\ddagger)$ or Mann-Whitney test $(\dagger)$.

\subsection{Increased $\mathrm{HO}-1$ levels and relative expression are tissue-dependent}

Increased HO-1 levels and relative expression in human VL patients have been correlated with disease susceptibility (Das et al., 2013; Luz et al., 2012). Until now, the role of HO-1 had not been investigated in relation to CVL. With the aim of ascertaining the involvement of HO-1 in the disease pathogeny of susceptible dogs, we determined the levels and relative gene expression of HO-1 in infected dogs and compared them with healthy control dogs.

The infected dogs presented increased HO-1 levels in the plasma, spleen and PBMC; there was no difference in BMMC (Fig. 2A). Increased relative expression of $\mathrm{HO}-1$ was observed in the PBMC and BMMC of infected dogs, with no significant differences in spleen tissue between infected and healthy dogs (Fig. 2B). 
A

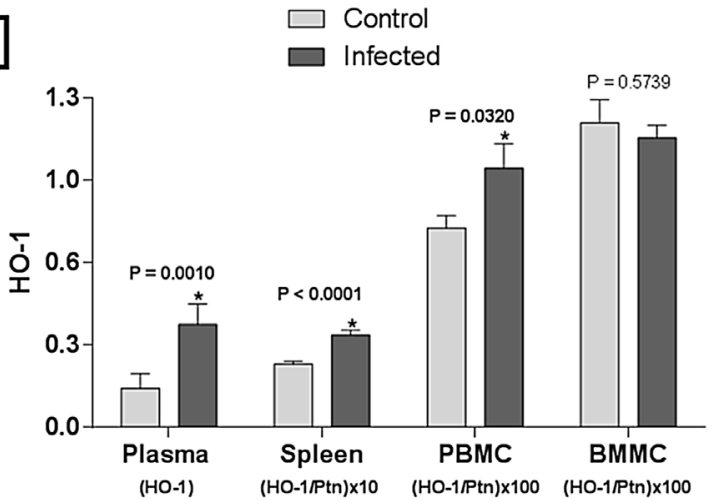

$B$

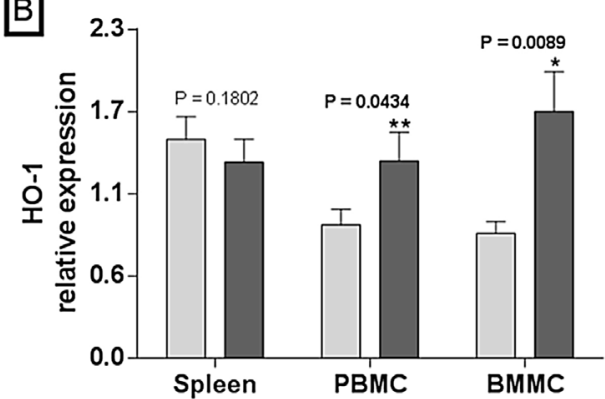

Fig. 2. Levels of heme oxygenase-1 (HO-1) determined in plasma, spleen homogenate, peripheral blood (PBMC) or bone marrow (BMMC) mononuclear cells normalized to protein levels in control dogs (Control, plasma HO-1 $\mathrm{n}=24$ and other variables $\mathrm{n}=10$ ) and dogs with naturally occurring canine visceral leishmaniasis (Infected, plasma HO-1 $n=20$ and other variables $n=10)(A)$. Relative expression of HO-1 normalized using geometric mean of standard expression of the genes betaactin and HPRT-1 in spleen, PBMC and BMMC of control dogs (Control, $\mathrm{n}=10)$ and dogs with naturally occurring canine visceral leishmaniasis (Infected, $n=10$ ) (B). The graphs show the mean and standard error of the mean. Statistically significant differences are indicated by * (unpaired $t$-test) or ** (Mann-Whitney test).

\subsection{Increased levels of heme metabolism substances and IL-10 in CVL}

In addition to determining $\mathrm{HO}-1$, we also assessed the IL-10 and HO-1 enzymatic metabolic pathway in infected dogs by determining the levels of plasma-free heme and the levels of ferritin, haptoglobin and sCD163 in the plasma and spleen of dogs. Similarly to HO-1, the plasma and spleen levels of IL-10, ferritin, sCD163 and haptoglobin were elevated in the infected dogs (Figs. 3 and 4). The plasma-free heme levels were not altered by the infection (Fig. 3A).

\subsection{HO-1 correlated with oxidative stress markers and IL-10, but not with the parasite load}

With the aim of ascertaining the correlation between HO-1, oxidative stress and parasite load, these parameters were correlated with $\mathrm{HO}-1$ levels and relative gene expression. We observed that the HO-1 levels in bone marrow had a positive correlation with plasma TOC and that the HO-1 levels in the spleen had a positive correlation with lipid peroxidation, while the spleen HO- 1 levels had negative correlations with the plasma antioxidants albumin, total bilirubin, indirect bilirubin and TAC. The HO-1 levels in bone marrow also correlated negatively with albumin, total bilirubin and indirect bilirubin (Table 3).

The plasma and spleen levels of IL-10 correlated positively with plasma HO-1 levels, while spleen IL-10 also correlated positively with spleen $\mathrm{HO}-1$ levels and BMMC HO- 1 relative gene expression. There was no correlation between the parasite load and HO-1 in the infected dogs (Table 3 ).

\subsection{Inhibition of HO-1 increases lymphoproliferation induced by antigens of $\mathrm{L}$. infantum in LNCs from infected dogs}

Because of the increased HO- 1 metabolism in CVL, we aimed to determine whether inhibition of $\mathrm{HO}-1$ might improve the
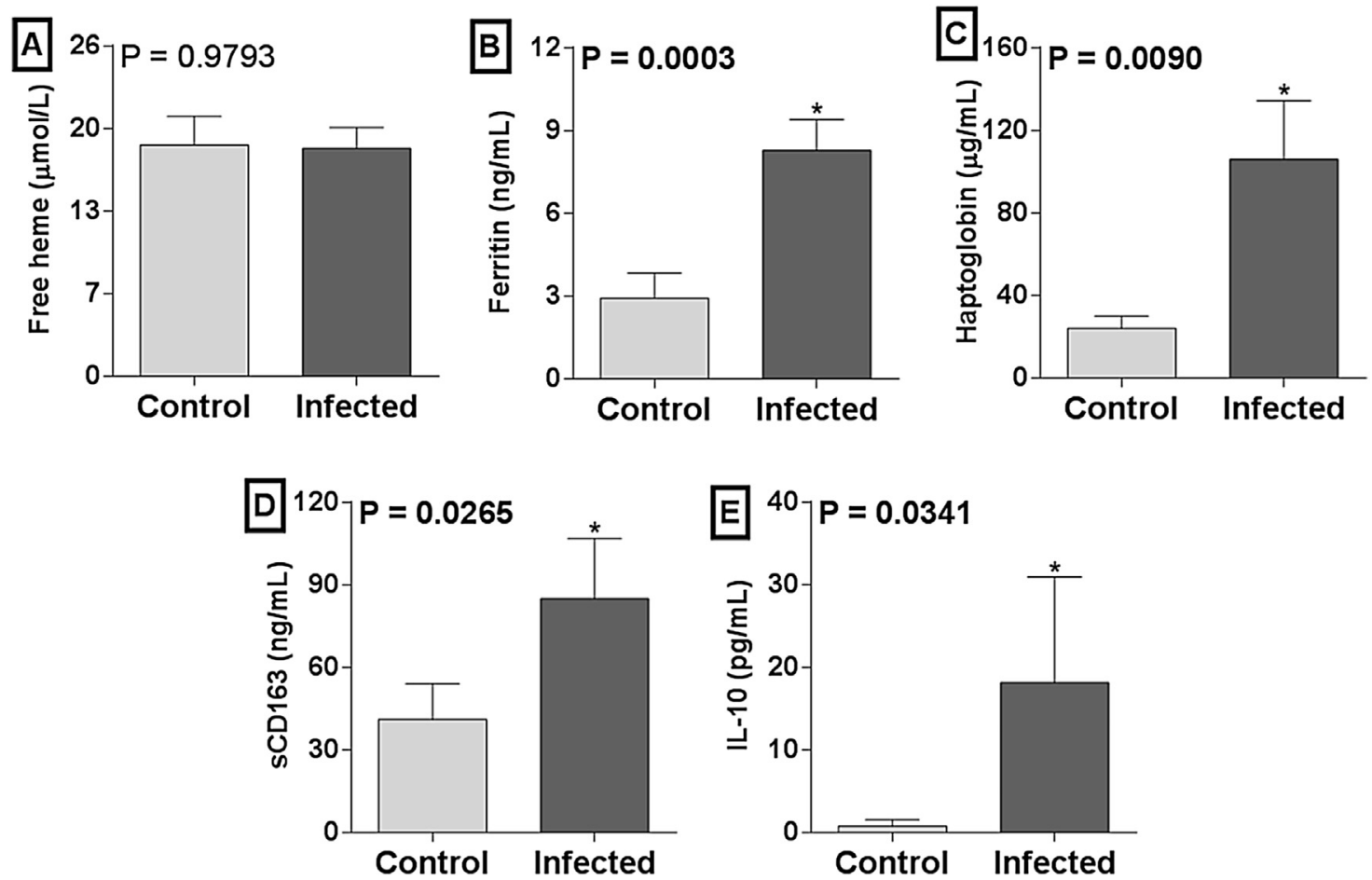

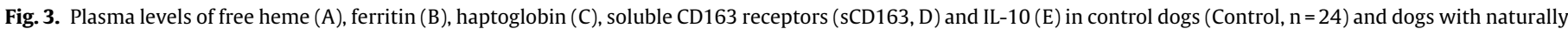

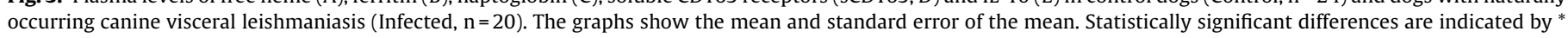
(Mann-Whitney test). 
Table 3

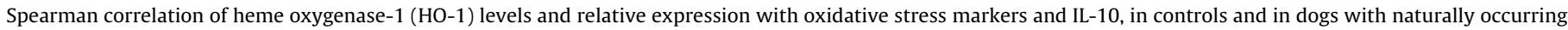
visceral leishmaniasis, and correlation of HO-1 levels and expression with parasite load in infected dogs.

\begin{tabular}{|c|c|c|c|c|c|c|c|}
\hline Parameter & $\begin{array}{l}\text { Plasma } \\
\text { HO-1 } \\
\text { (ELISA) }\end{array}$ & $\begin{array}{l}\text { PBMC } \\
\text { HO-1 } \\
\text { (ELISA) }\end{array}$ & $\begin{array}{l}\text { BMMC } \\
\text { HO-1 } \\
\text { (ELISA) }\end{array}$ & $\begin{array}{l}\text { Spleen } \\
\text { HO-1 } \\
\text { (ELISA) }\end{array}$ & $\begin{array}{l}\text { PBMC } \\
\text { HO-1 } \\
\text { expression }\end{array}$ & $\begin{array}{l}\text { BMMC } \\
\text { HO-1 } \\
\text { expression }\end{array}$ & $\begin{array}{l}\text { Slpeen } \\
\text { HO-1 } \\
\text { expression }\end{array}$ \\
\hline Albumin & $P=0.0509$ & $P=0.5137$ & $P=0.1451$ & $\begin{array}{l}P=0.0026 \\
r=-0.6361\end{array}$ & $P=0.1043$ & $\begin{array}{l}P=0.0016 \\
r=-0.6571\end{array}$ & $P=0.5801$ \\
\hline Uric acid & $P=0.9069$ & $P=0.7984$ & $P=0.9233$ & $\mathrm{P}=0.0675$ & $\mathrm{P}=0.8888$ & $\begin{array}{l}P=0.0414 \\
r=0.4597\end{array}$ & $P=0.5264$ \\
\hline Total bilirubin & $P=0.5177$ & $P=0.4543$ & $P=0.2077$ & $\begin{array}{l}P=0.0084 \\
r=-0.5724\end{array}$ & $P=0.7924$ & $\begin{array}{l}P=0.0103 \\
r=-0.5596\end{array}$ & $\mathrm{P}=0.2741$ \\
\hline Direct bilirubin & $P=0.3531$ & $P=0.9399$ & $P=0.6278$ & $\mathrm{P}=0.1356$ & $\begin{array}{l}P=0.0334 \\
r=0.3414\end{array}$ & $\begin{array}{l}P=0.0160 \\
r=0.5308\end{array}$ & $P=0.3502$ \\
\hline Indirect bilirubin & $\mathrm{P}=0.8162$ & $P=0.2383$ & $P=0.1884$ & $\begin{array}{l}P=0.0022 \\
r=-0.6431\end{array}$ & $\mathrm{P}=0.2619$ & $\begin{array}{l}P=0.0072 \\
r=-0.5814\end{array}$ & $P=0.1609$ \\
\hline TAC & $P=0.4631$ & $\mathrm{P}=0.2708$ & $P=0.8723$ & $\begin{array}{l}P=0.0099 \\
r=-0.5620\end{array}$ & $\mathrm{P}=0.8988$ & $\mathrm{P}=0.6195$ & $\mathrm{P}=0.8846$ \\
\hline TOC & $P=0.5378$ & $\mathrm{P}=0.4413$ & $\begin{array}{l}P=0.0020 \\
r=0.6632\end{array}$ & $P=0.3695$ & $\mathrm{P}=0.0852$ & $P=0.6224$ & $\mathrm{P}=0.2928$ \\
\hline TBARS & $P=0.0730$ & $\mathrm{P}=0.4641$ & $P=0.2809$ & $\begin{array}{l}P=0.0227 \\
r=0.5064\end{array}$ & $P=0.3083$ & $P=0.2426$ & $P=0.0608$ \\
\hline Plasma IL-10 & $\begin{array}{l}P=0.0275 \\
r=0.4921\end{array}$ & $P=0.1739$ & $P=0.5126$ & $\mathrm{P}=0.1988$ & $P=0.4696$ & $P=0.2529$ & $P=0.2014$ \\
\hline Spleen IL-10 & $\begin{array}{l}P=0.0218 \\
r=0.5093\end{array}$ & $P=0.4263$ & $P=0.8250$ & $\begin{array}{l}P=0.0001 \\
r=0.7564\end{array}$ & $P=0.4523$ & $\begin{array}{l}P=0.0405 \\
r=0.4617\end{array}$ & $P=0.3851$ \\
\hline Spleen parasite load & $P=0.3923$ & $P=0.3363$ & $P=0.3869$ & $P=0.3129$ & $P=0.7723$ & $P=0.7850$ & $P=0.7330$ \\
\hline Bone marrow parasite load & $P=0.6244$ & $P=0.463$ & $P=0.8916$ & $P=0.0806$ & $P=0.1777$ & $P=0.6821$ & $\mathrm{P}=0.8382$ \\
\hline
\end{tabular}

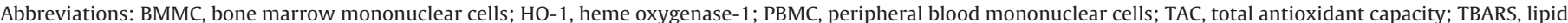
peroxidation determined via thiobarbituric acid reactive substances; TOC, total oxidant capacity.
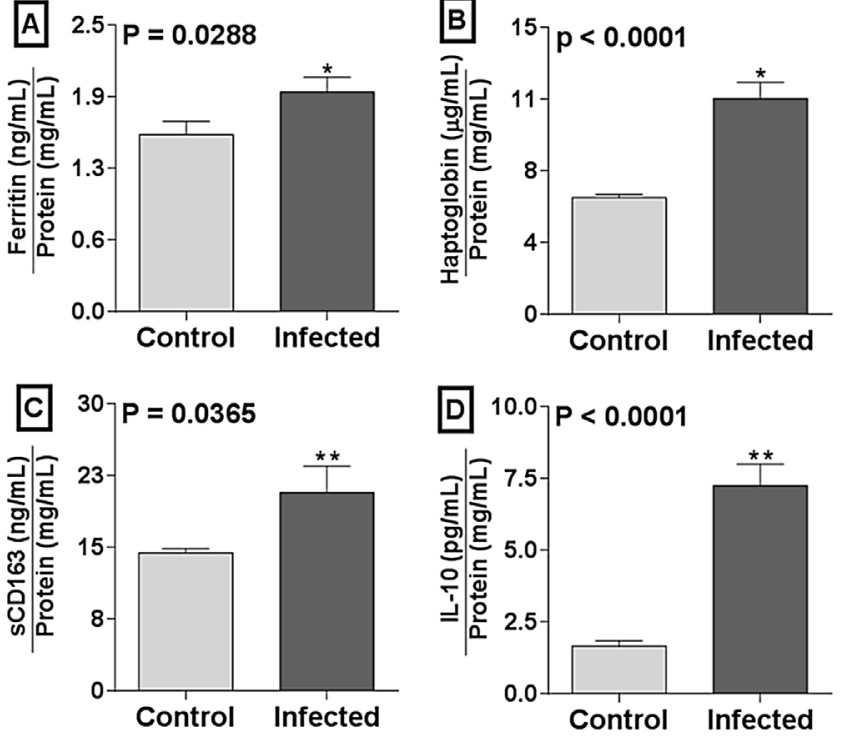

Fig. 4. Spleen homogenate levels of ferritin (A), haptoglobin (B), soluble CD163 receptor (sCD163, C) and IL-10 (D) normalized to protein levels in control dogs (Control, $\mathrm{n}=10$ ) and dogs with naturally occurring canine visceral leishmaniasis (Infected, $\mathrm{n}=10$ ). The graphs show the mean and standard error of the mean. Statistically significant differences are indicated by * (unpaired $t$-test) or ** (Mann-Whitney test).

proliferative response of LNCs in infected dogs. We observed that HO-1 inhibition using SnMsP significantly increased the LNCs proliferation from infected dogs both at the baseline and in the presence of SAgL, while HO- 1 activation using CoPP decreased the antigen-specific lymphoproliferation (Fig. 5A).

HO-1 activation with CoPP and inhibition with SnMsP, respectively, significantly increased and decreased the enzyme levels (Fig. 5B). However, when evaluating gene expression, only activation with CoPP increased HO-1 relative expression significantly, while inhibition with SnMsP did not alter HO-1 relative expression (Fig. 5C).

\subsection{The increase in LNCs proliferation involves decreased production of IL-10 and IL-2 through HO-1 inhibition}

After we had determined that HO-1 inhibition improved the antigen-specific lymphoproliferative response in infected dogs and that activation impaired it, we evaluated IL-10 because of its regulatory function in the lymphocyte proliferative response in VL (Strauss-Ayali et al., 2005). We also evaluated IL-2 because of its effect on the activation and proliferation of Tymphocytes (Santana and Rosenstein, 2003) and IFN-gamma because of its production during lymphocyte activation and association with disease resistance in canine infection (Pinelli et al., 1999a,b). We observed that HO-1 inhibition using SnMsP, verified through its reduced levels (Fig. 5B), occurred with decreased production of IL-2 (Fig. 6B) and IL-10 (Fig. 6C) in the LNCs culture supernatant from infected dogs.

The stimulation of LNCs from infected dogs with SAgL increased lymphoproliferation (Fig. 5A) and also decreased IL-2 production (Fig. 6B). Interestingly, both activation and inhibition of HO-1 caused a significant reduction in IL-2 levels, with greater decreases observed in the presence of the SnMsP HO-1 inhibitor (Fig. 6B), which also improved the proliferation rate (Fig. 5A).

The production of IFN-gamma did not consistently change with HO-1 inhibition or activation. IFN-gamma production was reduced in the presence of the HO-1 activator without SAgL, while an increasing trend (not statistically significant) was observed in the presence of SAgL (Fig. 6A).

The ConA mitogen induced the greatest cell proliferation rate (Fig. 5A). This occurred with inhibition of HO-1 relative expression (Fig. 5C) and with higher IFN-gamma, IL-2 and IL-10 production (Fig. 6).

A negative correlation was observed between $\mathrm{HO}-1$ relative expression and the LNCs proliferation rate in the presence of SAgL $(\mathrm{P}=0.0213, \mathrm{r}=-0.4185)$. This indicated that $\mathrm{HO}-1$ relative expression increased when cell proliferation decreased. 

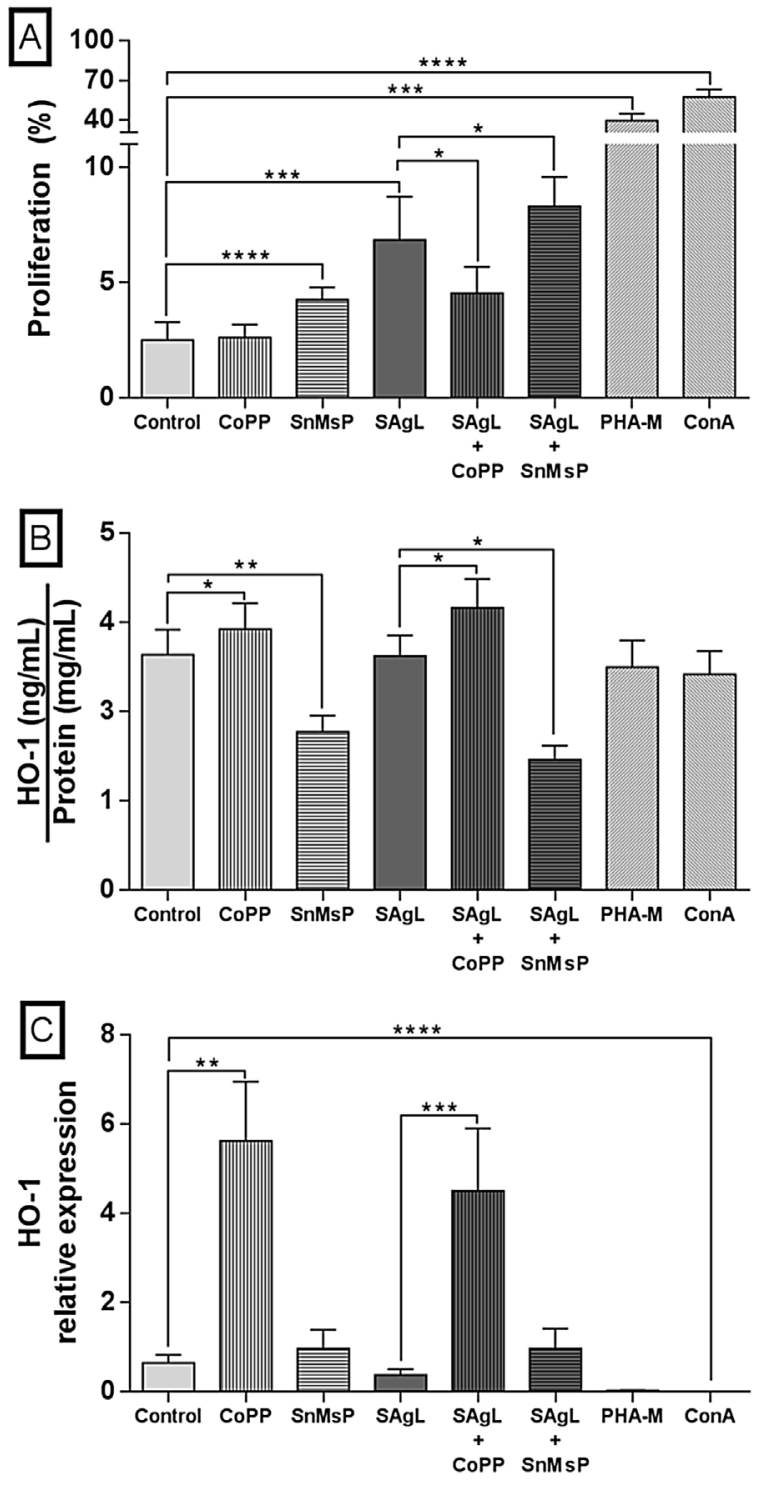

Fig. 5. Proliferation rate of lymph node cells from dogs with naturally occurring visceral leishmaniasis $(\mathrm{n}=15)$ stained with CFSE that were cultured for six days without any treatment (control) in the presence of the mitogens phytohemagglutinin-M (PHA-M) and concanavalin-A (ConA), and the soluble antigen of Leishmania infantum (SAgL) with or without associated cobaltic protoporphyrin IX chloride (CoPP) and $\mathrm{Sn}$ (IV) mesoporphyrin IX dichloride (SnMsP) (A). Heme oxygenase-1 (HO-1) levels measured by means of capture ELISA and normalized to protein levels from lymph cells without CFSE labeling, which had been subjected to the same treatments as described previously (B). HO-1 relative expression determined by means of qRTPCR and normalized according to the geometric mean of the standard expression of the genes beta-actin and HPRT- 1 from lymph cells without CFSE labeling that had been subjected to the same treatments as described previously (C). The graphs show the mean and standard error of the mean. Statistics: Friedman test with Dunn's multiple comparison. ${ }^{*} \mathrm{P}<0.05,{ }^{* *} \mathrm{P}<0.01,{ }^{* * *} \mathrm{P}<0.001,{ }^{* * * *} \mathrm{P}<0.0001$.

\section{Discussion}

We demonstrated that dogs with CVL present oxidative stress associated with increased levels and relative gene expression of HO-1. Positive correlations were observed between HO-1 and oxidizing substances, and negative correlations were observed between $\mathrm{HO}-1$ and anti-oxidant substances. Our data also revealed that increases in HO-1 levels correlated with increased IL-10 production. The antigen-specific lymphoproliferative responses from lymph node cells of infected dogs decreased with HO-1 activation and increased with HO-1 inhibition. This increase coincided
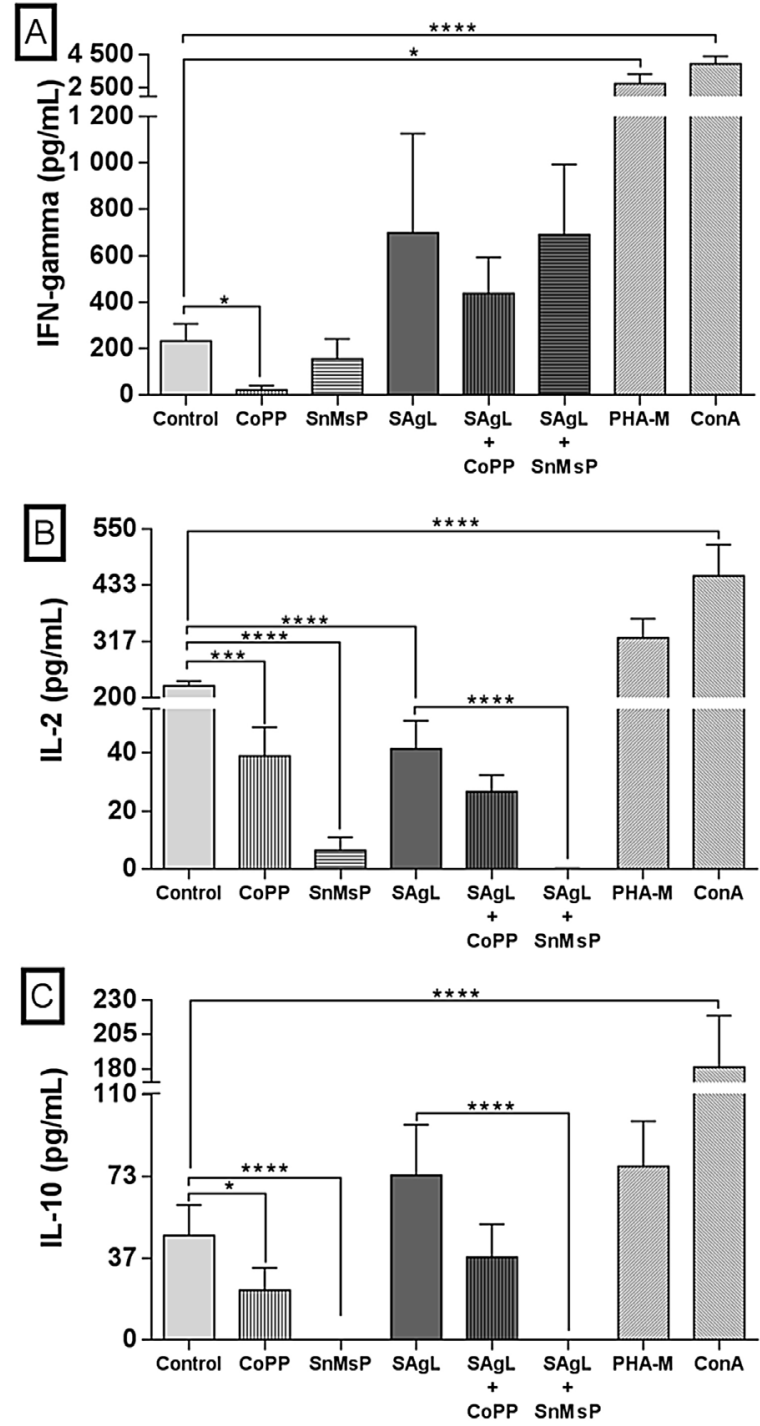

Fig. 6. Interferon-gamma (IFN-gamma, A), IL-2 (B) and IL-10 (C) measured from the supernatant of lymph node cells that were cultured for six days from dogs with naturally occurring visceral leishmaniasis $(n=15)$ without any treatment (control) and in the presence of the mitogens phytohemagglutinin-M (PHA-M) and concanavalinA (ConA), and the soluble antigen of Leishmania infantum (SAgL) with or without associated cobaltic protoporphyrin IX chloride (CoPP) and $\mathrm{Sn}(\mathrm{IV})$ mesoporphyrin IX dichloride (SnMsP). The graphs show the mean and standard error of the mean. Statistics: Friedman test with Dunn's multiple comparison. ${ }^{*} \mathrm{P}<0.05,{ }^{* *} \mathrm{P}<0.01,{ }^{* * *}$ $\mathrm{P}<0.001,{ }^{* * * *} \mathrm{P}<0.0001$.

with reductions in IL-10 and IL-2 levels in the cell culture supernatant. These data demonstrate that the increased HO-1 in CVL is likely to be one of the mechanisms responsible for reducing cellular immunity and impaired lymphoproliferative responses in infected dogs.

The oxidative stress observed in CVL was due to reduced antioxidant levels and increased oxidant levels. This resulted in enhanced lipid peroxidation in infected dogs, which is consistent with our previous report (Almeida et al., 2013b). Although the levels of uric acid (an antioxidant) were higher in infected dogs, this was not enough to improve oxidative stress because TAC remained low in these animals.

The positive correlation between HO- 1 and oxidants and the negative correlation between $\mathrm{HO}-1$ and antioxidants is the first evidence of the relationship between oxidative stress and increased HO-1 levels and relative gene expression in dogs. However, it has been shown that HO- 1 is activated by stress in other species 
(Vile et al., 1994). These findings suggest that higher oxidant production and lipid peroxidation reduce the antioxidant levels and increase the HO-1 production by blood and bone marrow monocytes/macrophages in infected dogs. A previous report demonstrated the possibility of development of oxidative stress in humans with VL caused by $L$. donovani infection, which revealed increased HO-1 levels, increased sorbitol dehydrogenase activity and reduced glutathione peroxidase activity. These alterations were reversed after treatment (Das et al., 2013). There was no correlation between $\mathrm{HO}-1$ and the parasite load in the spleens and bone marrow of infected dogs, thus suggesting that oxidative stress has a more important role in $\mathrm{HO}-1$ increases in infected dogs than the number of parasites.

Although HO-1 exhibits antioxidant effects and is increased in CVL, oxidative stress still remained evident in infected dogs, which may have contributed to anemia in these dogs (Britti et al., 2008). Additionally, plasma HO-1 levels correlated negatively with RBC $(\mathrm{r}=-0.3595, \mathrm{P}=0.0210)$, hemoglobin $(\mathrm{r}=-0.4728, \mathrm{P}=0.0021)$ and PCV $(r=-0.4369, P=0.0043)$ (data not shown). These correlations point towards an association between increased HO-1 levels and anemia in infected dogs because HO- 1 is responsible for metabolizing the heme in hemoglobin (Tenhunen et al., 1969). It is important to highlight that HO-1 is a microsomal enzyme and possibly presents no plasma activity (Tenhunen et al., 1969; Yoshinaga et al., 1982). Moreover, our methodology to determine HO-1 plasma levels using capture ELISA only determined the plasma protein content. However, increased plasma levels of $\mathrm{HO}-1$ are possibly caused by higher synthesis of this enzyme and/or injury in tissues responsible for heme degradation such as the liver or spleen (Tenhunen et al., 1969).

The clinical signs and laboratory abnormalities were similar to those in previous studies (Almeida et al., 2013a,b; Ikeda-Garcia et al., 2008). Additionally, we observed that blood basophil counts were also increased, which had not been reported previously, in other studies examining CVL in infected dogs. We observed increased activity of the muscle injury enzymes AST, CK and LDH in the plasma of infected dogs, compared with uninfected dogs, which might predict muscle injury, as has been shown in previous studies on dogs with VL (Paciello et al., 2009; Vamvakidis et al., 2000).

However, with the exception of CK activity, it is important to emphasize that the other enzymes were within the reference range for dogs. Controls and infected dogs presented CK activity beyond the reference range interval, possibly due to the short reference interval proposed by Kaneko et al. (2008), since other studies have proposed longer intervals for healthy dogs (Lucas et al., 2015; Vamvakidis et al., 2000).

This study was the first to report increased HO-1 levels in the plasma, spleen and PBMC of infected dogs, hence suggesting that the HO-1 enzyme is involved in the pathogenesis of CVL. Studies evaluating $\mathrm{HO}-1$ in VL are still scarce and most involve in vitro studies with macrophages (El Fadili et al., 2008; Luz et al., 2012; Pham et al., 2005). In vivo studies have demonstrated elevated HO-1 serum levels in symptomatic human patients infected with L. infantum (Luz et al., 2012) and L. donovani (Das et al., 2013) and have shown that these values were reduced after treatment with miltefosine (Das et al., 2013) and meglumine antimoniate (Luz et al., 2012). Similarly to results in humans, increased HO-1 levels in dogs presenting with clinical signs of VL also seem to be related to increased disease susceptibility. However, studies examining HO-1 in resistant asymptomatic dogs are required to support this hypothesis.

HO-1 relative expression was only increased in PBMC and BMMC in dogs with VL. There were no differences in spleen tissue. A similar study in symptomatic human patients infected with $L$. donovani showed increased HO-1 gene expression in PBMC and in the splenic aspirate of those patients, with no alterations in bone marrow aspirate (Das et al., 2013). The discrepancies between these results and ours may be attributable to differences in the hosts, Leishmania spp. strains and disease stages.

In addition to the HO- 1 levels and relative expression, we evaluated part of the HO-1 metabolic pathway in the plasma and spleen. We observed increased levels of all substances, except for plasmafree heme. When hemoglobin is released from erythrocytes, it forms a stable complex with haptoglobin, which is recognized and internalized by splenic macrophages through the CD163 receptor of these cells (Tenhunen et al., 1969). Free iron, in turn, induces synthesis of ferritin, an important antioxidant that is responsible for transporting this substance (Balla et al., 1992). The increased levels of these metabolites in the plasma and spleens of infected dogs reinforce the increased hemoglobin metabolism in infected animals, as demonstrated by the negative correlations between HO- 1 and RBC, hemoglobin and PCV.

The unaltered free heme levels in infected dogs may be attributable to differences in hemoglobin metabolism. The heme is possibly degraded directly inside macrophages (extravascular hemolysis) in CVL, thereby avoiding formation of free heme. Increases in the levels of this metabolite have been described in intravascular hemolytic diseases, such as malaria (Andrade et al., 2010; Sinha et al., 2008). Both ferritin and haptoglobin are acutephase inflammatory proteins (Ceron et al., 2005) and increased serum levels of these substances have already been demonstrated in dogs with clinical VL (Martinez-Subiela et al., 2014; MartínezSubiela et al., 2002; Martinez-Subiela and Ceron, 2005). This indicates that the increase in these protein levels could also be a consequence of the inflammatory process.

Similarly to our results, increased levels of sCD163 have been demonstrated in the serum of human patients with LV (Schaer et al., 2005), with no previous reports in CVL. This receptor is restricted to cells of the macrophage lineage and demonstrates macrophage activation caused by infection (Law et al., 1993), which could also contribute to greater ferritin production (Ravelli, 2002). The role of the CD163 receptor in macrophage activation has not been fully elucidated. This receptor may exert pro-inflammatory activity, through inducing secretion of proinflammatory cytokines (Van den Heuvel et al., 1999), or it may exert anti-inflammatory activity, in which cytokines such as IL-10 can induce CD163 expression (Sulahian et al., 2000). These results support our findings, given that we observed increased concentrations of IL-10 and sCD163 in infected dogs. Thus, the inflammation and oxidative stress that occur in CVL appear to contribute to the increases in HO-1 levels and relative gene expression, as well as to increased macrophage activation and hemoglobin metabolism, thereby leading to increased concentrations of haptoglobin, ferritin and sCD163.

Since we observed increased HO-1 metabolism in susceptible dogs with VL, we assessed whether inhibition of HO- 1 could improve the proliferative response of lymph node cells from infected dogs. Additionally, we identified the cytokines involved in this process, given that it has been determined that infected dogs have impaired cellular immunity (Baneth et al., 2008). We observed reductions in the antigen-specific LNCs proliferative response through activation of HO- 1 and increased proliferation of these cells with reduced HO-1 levels. Negative correlations between HO-1 relative expression and the antigen-specific lymphoproliferation rate were also observed.

This is the first evidence that HO-1 inhibition with SnMsP improves the antigen-specific proliferative response in lymph node cells of infected dogs. Previous studies in humans have shown that SnMsP increases unspecific proliferation of T CD3+ cells (Bunse et al., 2015; Burt et al., 2010) through inducing expression of costimulatory molecules on monocytes, such as CD86 (B7-2), and optimizing the antigen presentation process (Burt et al., 2010). In CVL, it is already known that the proliferative response of 
T lymphocytes is reduced due to suppression of B7 molecules in the macrophages of infected dogs (Pinelli et al., 1999a,b). Thus, one of the possible mechanisms activated through HO- 1 inhibition could involve restoration of these molecules, thereby optimizing cell activation and proliferation.

IL-10, an important anti-inflammatory interleukin, was increased in the plasma and spleens of infected dogs. This increase correlated positively with $\mathrm{HO}-1$ levels and relative gene expression, and its synthesis was suppressed by HO- 1 inhibition in LNCs cultures from infected dogs. These findings suggest that there is a relationship between HO- 1 and IL-10 levels, in which increased levels of this cytokine appear to stimulate HO-1 synthesis, or vice versa, thus contributing to the impaired lymphoproliferative response of sick dogs. This positive correlation between HO-1 and IL-10 has been demonstrated in humans with VL (Luz et al., 2012) and is consistent with other studies that have claimed that IL-10 induces HO-1 gene expression in human monocytes that are stimulated with lipopolysaccharide (Petit-Bertron et al., 2003) and in murine macrophages (Lee and Chau, 2002). Furthermore, activation of HO-1 activity causes increased production of carbon monoxide (CO), which also increases the levels of antiinflammatory cytokines such as IL-10 (Brouard et al., 2000), thus confirming our results from infected dogs and cultured LNCs from these animals.

We observed that HO-1 inhibition with SnMsP in the presence of $L$. infantum antigen significantly reduced IL-2 levels and increased LNCS proliferation. Although it has been accepted that increased IL-2 is required for full activation and proliferation of CD4+ T lymphocytes (Santana and Rosenstein, 2003), other studies have demonstrated that this cytokine has an immunoregulatory role (Bachmann and Oxenius, 2007). High IL-2 levels would be crucial for activation of Treg lymphocytes (Brunkow et al., 2001; Fontenot et al., 2003) and could induce cell death in lymphocytes via FAS/FAS-L after repeated stimulation (Krammer, 2000). However further studies to determine IL-2 function in CVL antigenspecific proliferation are needed.

Use of SnMsP was effective in improving the proliferative response of LNCs, but did not inhibit HO-1 relative expression. Other studies have shown increasing HO-1 relative expression due to SnMsP (Burt et al., 2010) and due to other inhibitors, such as zinc protoporphyrin IX (El Fadili et al., 2008). This suggests that the decreased HO-1 levels resulted from inhibition at a posttranscriptional level.

Given that dogs with CVL exhibit increased HO-1 metabolic pathway activity and that the HO- 1 enzyme has immunoregulatory effects on cell proliferation (Listopad et al., 2007), we demonstrated that HO-1 inhibition improves cellular immunity in infected animals. Thus, new therapeutic approaches for CVL should consider using pharmacological HO-1 inhibitors along with antioxidants, to reduce oxidative stress under these conditions. Evaluation of whether oxidative stress is the only factor that is responsible for HO-1 activation in infected dogs should be considered in other studies, since HO- 1 is known to be activated by stress conditions.

\section{Conclusion}

Increased HO-1 metabolism is associated with oxidative stress and IL-10 and appears to be one of the mechanisms involved in inhibition of cellular immunity in dogs with visceral leishmaniasis, thereby impairing the lymphoproliferative response of sick dogs.

\section{Conflict of interest}

The authors declare that there were no financial or commercial conflicts of interest.

\section{Acknowledgements}

The authors are grateful to the State of São Paulo Research Support Foundation (FAPESP) for its financial support (Proc. 2013/07496-1 and 2013/06068-6) and to Flavia Mari Yamamoto and Laine Margareth Gabas for valuable laboratory assistance.

\section{References}

Almeida, B.F.M., Narciso, L.G., Bosco, A.M., Pereira, P.P., Braga, E.T., Avanço, S.V Marcondes, M., Ciarlini, P.C., 2013a. Neutrophil dysfunction varies with the stage of canine visceral leishmaniosis. Vet. Parasitol. 196, 6-12, http://dx.doi. org/10.1016/j.vetpar.2013.02.016.

Almeida, B.F.M., Narciso, L.G., Melo, L.M., Preve, P.P., Bosco, A.M., Lima, V.M.F., Ciarlini, P.C., 2013b. Leishmaniasis causes oxidative stress and alteration of oxidative metabolism and viability of neutrophils in dogs. Vet. J. 198, 599-605, http://dx.doi.org/10.1016/j.tvjl.2013.08.024.

Alvar, J., Cañavate, C., Molina, R., Moreno, J., Nieto, J., 2004. Canine Leishmaniasis. Adv. Parasitol. 57, 1-88, http://dx.doi.org/10.1016/S0065-308X(04)57001-X.

Alvar, J., Vélez, I.D., Bern, C., Herrero, M., Desjeux, P., Cano, J., Jannin, J., den Boer M., WHO Leishmaniasis Control Team, 2012. Leishmaniasis worldwide and global estimates of its incidence. PLoS One 7, e35671, http://dx.doi.org/10. 1371/journal.pone.0035671.

Andrade, B.B., Reis-Filho, A., Souza-Neto, S.M., Raffaele-Netto, I., Camargo, L.M.A., Barral, A., Barral-Netto, M., 2010. Plasma superoxide dismutase-1 as a surrogate marker of vivax malaria severity. PLoS Negl. Trop. Dis. 4, e650, http://dx.doi.org/10.1371/journal.pntd.0000650.

Bachmann, M.F., Oxenius, A., 2007. Interleukin 2: from immunostimulation to immunoregulation and back again. EMBO Rep. 8, 1142-1148, http://dx.doi.org/ 10.1038/sj.embor.7401099.

Balla, G., Jacob, H.S., Balla, J., Rosenberg, M., Nath, K., Apple, F., Eaton, J.W., Vercellotti, G.M., 1992. Ferritin: a cytoprotective antioxidant strategem of endothelium. J. Biol. Chem. 267, 18148-18153.

Baneth, G., Koutinas, A.F., Solano-Gallego, L., Bourdeau, P., Ferrer, L., Moreno, J., Alvar, J., Ferroglio, E., et al., 2008. Canine leishmaniosis - new concepts and insights on an expanding zoonosis: part one. Trends Parasitol. 24, 324-330, http://dx.doi.org/10.1016/j.pt.2008.04.001.

Bildik, A., Kargın, F., Seyrek, K., Pasa, S., Özensoy, S., 2004. Oxidative stress and non-enzymatic antioxidative status in dogs with visceral Leishmaniasis. Res. Vet. Sci. 77, 63-66, http://dx.doi.org/10.1016/j.rvsc.2004.01.005.

Boggiatto, P.M., Ramer-Tait, A.E., Metz, K., Kramer, E.E., Gibson-Corley, K., Mullin, K., Hostetter, J.M., Gallup, J.M., Jones, D.E., Petersen, C.A., 2010. Immunologic indicators of clinical progression during canine Leishmania infantum infection. Clin. Vaccine Immunol. 17, 267-273, http://dx.doi.org/10.1128/CVI. 00456-09.

Britti, D., Sconza, S., Morittu, V.M., Santori, D., Boari, A., 2008. Superoxide dismutase and Glutathione peroxidase in the blood of dogs with Leishmaniasis. Vet. Res. Commun. 32 (Suppl. 1), S251-4, http://dx.doi.org/10. 1007/s11259-008-9121-3.

Brouard, S., Otterbein, L.E., Anrather, J., Tobiasch, E., Bach, F.H., Choi, A.M., Soares, M.P., 2000. Carbon monoxide generated by heme oxygenase 1 suppresses endothelial cell apoptosis. J. Exp. Med. 192, 1015-1026.

Brunkow, M.E., Jeffery, E.W., Hjerrild, K.A., Paeper, B., Clark, L.B., Yasayko, S.A., Wilkinson, J.E., Galas, D., Ziegler, S.F., Ramsdell, F., 2001. Disruption of a new forkhead/winged-helix protein, scurfin, results in the fatal lymphoproliferative disorder of the scurfy mouse. Nat. Genet. 27, 68-73, http://dx.doi.org/10.1038/ 83784.

Bunse, C.E., Fortmeier, V., Tischer, S., Zilian, E., Figueiredo, C., Witte, T., Blasczyk, R., Immenschuh, S., Eiz-Vesper, B., 2015. Modulation of heme oxygenase-1 by metalloporphyrins increases anti-viral T cell responses. Clin. Exp. Immunol. 179, 265-276, http://dx.doi.org/10.1111/cei.12451.

Burt, T.D., Seu, L., Mold, J.E., Kappas, A., McCune, J.M., 2010. Naive human T cells are activated and proliferate in response to the heme oxygenase-1 inhibitor tin mesoporphyrin. J. Immunol. 185, 5279-5288, http://dx.doi.org/10.4049/ jimmunol.0903127.

Ceron, J.J., Eckersall, P.D., Martýnez-Subiela, S., 2005. Acute phase proteins in dogs and cats: current knowledge and future perspectives. Vet. Clin. Pathol. 34, 85-99.

Chiku, V.M., Silva, K.L.O., de Almeida, B.F.M., Venturin, G.L., Leal, A.A.C., de Martini, C.C., de Rezende Eugênio, F., dos Santos, P.S.P., de Lima, V.M.F., 2016. PD-1 function in apoptosis of T lymphocytes in canine visceral leishmaniasis. Immunobiology 221, 879-888, http://dx.doi.org/10.1016/j.imbio.2016.03.007.

Corrêa, A.P.F.L., Dossi, A.C.S., de Oliveira Vasconcelos, R., Munari, D.P., de Lima, V.M.F., 2007. Evaluation of transformation growth factor $\beta 1$, interleukin-10, and interferon- $\gamma$ in male symptomatic and asymptomatic dogs naturally infected by Leishmania (Leishmania) chagasi. Vet. Parasitol. 143, 267-274, http://dx.doi.org/10.1016/j.vetpar.2006.08.023.

Coura-Vital, W., Marques, M.J., Veloso, V.M., Roatt, B.M., Aguiar-Soares, R.D., de, O., Reis, L.E.S., Braga, S.L., Morais, M.H.F., Reis, A.B., Carneiro, M., 2011. Prevalence and factors associated with Leishmania infantum infection of dogs from an urban area of Brazil as identified by molecular methods. PLoS Negl. Trop. Dis. 5 e1291, http://dx.doi.org/10.1371/journal.pntd.0001291.

Das, S., Pandey, K., Rabidas, V.N., Mandal, A., Das, P., 2013. Effectiveness of miltefosine treatment in targeting anti-leishmanial HO-1/Nrf-2-mediated 
oxidative responses in visceral leishmaniasis patients. J. Antimicrob. Chemother. 68, 2059-2065, http://dx.doi.org/10.1093/jac/dkt162.

El Fadili, K., Imbeault, M., Messier, N., Roy, G., Gourbal, B., Bergeron, M., Tremblay, M.J., Légaré, D., Ouellette, M., 2008. Modulation of gene expression in human macrophages treated with the anti-leishmania pentavalent antimonial drug sodium stibogluconate. Antimicrob. Agents Chemother. 52, 526-533, http://dx doi.org/10.1128/AAC.01183-07.

Erel, O., 2004. A novel automated direct measurement method for total antioxidant capacity using a new generation, more stable ABTS radical cation. Clin. Biochem. 37, 277-285, http://dx.doi.org/10.1016/j.clinbiochem.2003.11.015.

Erel, O., 2005. A new automated colorimetric method for measuring total oxidant status. Clin. Biochem. 38, 1103-1111, http://dx.doi.org/10.1016/j.clinbiochem. 2005.08.008.

Fontenot, J.D., Gavin, M.A., Rudensky, A.Y., 2003. Foxp3 programs the development and function of CD4+CD25+ regulatory T cells. Nat. Immunol. 4, 330-336, http://dx.doi.org/10.1038/ni904.

Gramiccia, M., Gradoni, L., 2005. The current status of zoonotic leishmaniases and approaches to disease control. Int. J. Parasitol. 35, 1169-1180, http://dx.doi. org/10.1016/j.ijpara.2005.07.001.

Heidarpour, M., Soltani, S., Mohri, M., Khoshnegah, J., 2012. Canine visceral leishmaniasis: relationships between oxidative stress, liver and kidney variables, trace elements, and clinical status. Parasitol. Res. 111, 1491-1496 http://dx.doi.org/10.1007/s00436-012-2985-8.

Hunter, M.I., Nlemadim, B.C., Davidson, D.L., 1985. Lipid peroxidation products and antioxidant proteins in plasma and cerebrospinal fluid from multiple sclerosis patients. Neurochem. Res. 10, 1645-1652.

Ikeda-Garcia, F., Ciarlini, P., Lopes, R., 2008. Hematological evaluation of dogs naturally infected by Leishmania (Leishmania) chagasi submitted to treatment with meglumine antimoniate. Braz. J. Vet. Res, 45, 48-64.

Kaneko, J.J., Harvey, J.W., Bruss, M.L., 2008. Clinical Biochemistry of Domestic Animals, 6th ed. Academic Press, London.

Krammer, P.H., 2000. CD95's deadly mission in the immune system. Nature 407, 789-795, http://dx.doi.org/10.1038/35037728.

Kristiansen, M., Graversen, J.H., Jacobsen, C., Sonne, O., Hoffman, H.J., Law, S.K., Moestrup, S.K., 2001. Identification of the haemoglobin scavenger receptor. Nature 409, 198-201, http://dx.doi.org/10.1038/35051594.

Law, S.K., Micklem, K.J., Shaw, J.M., Zhang, X.P., Dong, Y., Willis, A.C., Mason, D.Y., 1993. A new macrophage differentiation antigen which is a member of the scavenger receptor superfamily. Eur. J. Immunol. 23, 2320-2325, http://dx.doi. org/10.1002/eji.1830230940.

Lee, T.-S., Chau, L.-Y., 2002. Heme oxygenase-1 mediates the anti-inflammatory effect of interleukin-10 in mice. Nat. Med. 8, 240-246, http://dx.doi.org/10. $1038 / \mathrm{nm} 0302-240$.

Lima, V.M.F., Gonçalves, M.E., Ikeda, F.A., Luvizotto, M.C.R., Feitosa, M.M., 2003 Anti-leishmania antibodies in cerebrospinal fluid from dogs with visceral leishmaniasis. Braz. J. Med. Biol. Res. 36, 485-489.

Lima, V.M.F., Fattori, de, de Souza, K.R., Eugênio, F., Santos, F.R., dos, P.S.P., Rozza, D.B., Machado, G.F., 2012. Apoptosis in T lymphocytes from spleen tissue and peripheral blood of L. (L.) chagasi naturally infected dogs. Vet. Parasitol. 184, 147-153, http://dx.doi.org/10.1016/j.vetpar.2011.08.024.

Listopad, J., Asadullah, K., Sievers, C., Ritter, T., Meisel, C., Sabat, R., Döcke, W.-D., 2007. Heme oxygenase- 1 inhibits T cell-dependent skin inflammation and differentiation and function of antigen-presenting cells. Exp. Dermatol. 16, 661-670, http://dx.doi.org/10.1111/j.1600-0625.2007.00581.x.

Lucas, V., Barrera, R., Duque, F.J., Ruiz, P., Zaragoza, C., 2015. Effect of exercise on serum markers of muscle inflammation in Spanish greyhounds. Am. J. Vet. Res. 76, 637-643, http://dx.doi.org/10.2460/ajvr.76.7.637.

Luz, N.F., Andrade, B.B., Feijó, D.F., Araújo-Santos, T., Carvalho, G.Q., Andrade, D., Abánades, D.R., Melo, E.V., Silva, A.M., Brodskyn, C.I., Barral-Netto, M., Barral, A., Soares, R.P., Almeida, R.P., Bozza, M.T., Borges, V.M., 2012. Heme oxygenase-1 promotes the persistence of Leishmania chagasi infection. J. Immunol. 188, 4460-4467, http://dx.doi.org/10.4049/jimmunol.1103072.

Lyons, A.B., Parish, C.R 1994. Determination of lymphocyte division by flow cytometry. J. Immunol. Methods 171, 131-137, http://dx.doi.org/10.1016 0022-1759(94)90236-4.

Martínez-Subiela, S., Tecles, F., Eckersall, P.D., Cerón, J.J., 2002. Serum concentrations of acute phase proteins in dogs with leishmaniasis. Vet. Rec. $150,241-244$.

Martinez-Subiela, S., Ceron, J., 2005. Evaluation of acute phase protein indexes in dogs with leishmaniasis at diagnosis, during and after short-term treatment. Vet. Med. (Praha) 50, 39-46.

Martinez-Subiela, S., Cerón, J.J., Strauss-Ayali, D., Garcia-Martinez, J.D., Tecles, F., Tvarijonaviciute, A., Caldin, M., Baneth, G., 2014. Serum ferritin and paraoxonase-1 in canine leishmaniosis. Comp. Immunol. Microbiol. Infect. Dis. 37, 23-29, http://dx.doi.org/10.1016/j.cimid.2013.10.004.

Nunes, C.M., Pires, M.M., da Silva, K.M., Assis, F.D., Filho, J.G., Perri, S.H.V., 2010. Relationship between dog culling and incidence of human visceral leishmaniasis in an endemic area. Vet. Parasitol. 170, 131-133, http://dx.doi. org/10.1016/j.vetpar.2010.01.044

Osborne, C.A., Stevens, J.B., Luilich, J.P., Al, E., 1995. A clinician's analysis of urinalysis. In: Osborne, C.A., Finco, D.R. (Eds.), Canine and Feline Nephrology and Urology. Williams \& Wilkins, Baltimore, pp. 136-205.

Paciello, O., Oliva, G., Gradoni, L., Manna, L., Foglia Manzillo, V., Wojcik, S., Trapani, F., Papparella, S., 2009. Canine inflammatory myopathy associated with Leishmania Infantum infection. Neuromuscul. Disord. 19, 124-130, http://dx. doi.org/10.1016/j.nmd.2008.10.013.
Pae, H.O., Oh, G.S., Choi, B.M., Chae, S.C., Kim, Y.M., Chung, K.R., Chung, H.T., 2004 Carbon monoxide produced by heme oxygenase- 1 suppresses T cell proliferation via inhibition of IL-2 production. J. Immunol. 172, 4744-4751.

Perosso, J., Silva, K.L.O., Ferreira, S.Í., de, S., Avanço, S.V., dos Santos, P.S.P., Eugênio F., de, R., de Almeida, B.F.M., de Lima, V.M.F., 2014. Alteration of sFAS and sFAS ligand expression during canine visceral leishmaniosis. Vet. Parasitol. 205, 417-423, http://dx.doi.org/10.1016/j.vetpar.2014.09.006.

Peters, I.R., Peeters, D., Helps, C.R., Day, M.J., 2007. Development and application of multiple internal reference (housekeeper) gene assays for accurate normalisation of canine gene expression studies. Vet. Immunol. Immunopathol. 117, 55-66, http://dx.doi.org/10.1016/j.vetimm.2007.01.011.

Petit-Bertron, A.-F., Fitting, C., Cavaillon, J.-M., Adib-Conquy, M., 2003. Adherence influences monocyte responsiveness to interleukin-10. J. Leukoc. Biol. 73, $145-154$.

Pham, N.-K., Mouriz, J., Kima, P.E., 2005. Leishmania pifanoi amastigotes avoid macrophage production of superoxide by inducing heme degradation. Infect. Immun. 73, 8322-8333, http://dx.doi.org/10.1128/IAI.73.12.8322-8333.2005.

Pinelli, E., Killick-Kendrick, R., Wagenaar, J., Bernadina, W., del Real, G., Ruitenberg J., 1994. Cellular and humoral immune responses in dogs experimentally and naturally infected with Leishmania infantum. Infect. Immun. 62, 229-235.

Pinelli, E., Rutten, V.P., Bruysters, M., Moore, P.F., Ruitenberg, E.J., 1999a. Compensation for decreased expression of B7 molecules on Leishmania infantum-infected canine macrophages results in restoration of parasite-specific T-cell proliferation and gamma interferon production. Infect. Immun. 67, 237-243.

Pinelli, E., van der Kaaij, S.Y., Slappendel, R., Fragio, C., Ruitenberg, E.J., Bernadina, W., Rutten, V.P.M.G., 1999b. Detection of canine cytokine gene expression by reverse transcription-polymerase chain reaction. Vet. Immunol. Immunopathol. 69, 121-126, http://dx.doi.org/10.1016/S01652427(99)00048-3.

Ravelli, A., 2002. Macrophage activation syndrome. Curr. Opin. Rheumatol. 14, $548-552$.

Rizzi, T.E., Meinkoth, J.H., Clinkenbeard, K.D., 2010. Normal hematology of the dog. In: Weiss, D.J., Wardrop, K.J. (Eds.), Schalm's Veterinary Hematology. Wiley-Blackwell, Philadelphia, pp. 799-810.

Santana, M.A., Rosenstein, Y., 2003. What it takes to become an effector T cell: the process, the cells involved, and the mechanisms. J. Cell. Physiol. 195, 392-401, http://dx.doi.org/10.1002/jcp.10258.

Schaer, D.J., Schleiffenbaum, B., Kurrer, M., Imhof, A., Bächli, E., Fehr, J., Moller, H.J., Moestrup, S.K., Schaffner, A., 2005. Soluble hemoglobin-haptoglobin scavenger receptor CD163 as a lineage-specific marker in the reactive hemophagocytic syndrome. Eur. J. Haematol. 74, 6-10, http://dx.doi.org/10.1111/j.1600-0609. 2004.00318.x.

Scott, P., Pearce, E., Natovitz, P., Sher, A., 1987. Vaccination against cutaneous leishmaniasis in a murine model. I. Induction of protective immunity with a soluble extract of promastigotes. J. Immunol. 139, 221-227.

Sinha, S., Mishra, S.K., Sharma, S., Patibandla, P.K., Mallick, P.K., Sharma, S.K., Mohanty, S., Pati, S.S., Mishra, S.K., Ramteke, B.K., Bhatt, R., Joshi, H., Dash, A.P., Ahuja, R.C., Awasthi, S., Indian Genome Variation Consortium, Habib, V., Habib, S., 2008. Polymorphisms of TNF-enhancer and gene for FcgammaRIIa correlate with the severity of falciparum malaria in the ethnically diverse Indian population. Malar. J. 7, 13, http://dx.doi.org/10.1186/1475-2875-7-13.

Solano-Gallego, L., Koutinas, A., Miró, G., Cardoso, L., Pennisi, M.G., Ferrer, L. Bourdeau, P., Oliva, G., Baneth, G., 2009. Directions for the diagnosis, clinical staging, treatment and prevention of canine leishmaniosis. Vet. Parasitol. 165, 1-18, http://dx.doi.org/10.1016/j.vetpar.2009.05.022.

Solano-Gallego, L., Montserrrat-Sangrà, S., Ordeix, L., Martínez-Orellana, P., 2016. Leishmania infantum-specific production of IFN- $\gamma$ and IL-10 in stimulated blood from dogs with clinical leishmaniosis. Parasites Vectors 9, 317, http://dx. doi.org/10.1186/s13071-016-1598-y.

Strauss-Ayali, D., Baneth, G., Shor, S., Okano, F., Jaffe, C.L., 2005. Interleukin-12 augments a Th1-type immune response manifested as lymphocyte proliferation and interferon gamma production in Leishmania infantum-infected dogs. Int. J. Parasitol. 35, 63-73, http://dx.doi.org/10.1016/j. ijpara.2004.10.015.

Sulahian, T.H., Högger, P., Wahner, A.E., Wardwell, K., Goulding, N.J., Sorg, C., Droste, A., Stehling, M., Wallace, P.K., Morganelli, P.M., Guyre, P.M., 2000. Human monocytes express CD163, which is upregulated by IL-10 and identical to $\mathrm{p} 155$. Cytokine 12, 1312-1321, http://dx.doi.org/10.1006/cyto.2000.0720.

Tenhunen, R., Marver, H.S., Schmid, R., 1969. Microsomal heme oxygenase. Characterization of the enzyme. J. Biol. Chem. 244, 6388-6394.

Vamvakidis, C.D., Koutinas, A.F., Kanakoudis, G., Georgiadis, G., Saridomichelakis, M., 2000. Masticatory and skeletal muscle myositis in canine leishmaniasis (Leishmania infantum). Vet. Rec. 146, 698-703.

Van den Heuvel, M.M., Tensen, C.P., van As, J.H., Van den Berg, T.K., Fluitsma, D.M., Dijkstra, C.D., Döpp, E.A., Droste, A., Van Gaalen, F.A., Sorg, C., Högger, P., Beelen, R.H., 1999. Regulation of CD 163 on human macrophages: cross-linking of CD163 induces signaling and activation. J. Leukoc. Biol. 66, 858-866.

Vile, G.F., Basu-Modak, S., Waltner, C., Tyrrell, R.M., 1994. Heme oxygenase 1 mediates an adaptive response to oxidative stress in human skin fibroblasts. Proc. Natl. Acad. Sci. U. S. A. 91, 2607-2610.

WHO World Health Organization, 2015. Investing to Overcome the Global Impact of Neglected Tropical Diseases. WHO, World Health Organization, Geneva.

Yoshinaga, T., Sassa, S., Kappas, A., 1982. Purification and properties of bovine spleen heme oxygenase. Amino acid composition and sites of action of inhibitors of heme oxidation. J. Biol. Chem. 257, 7778-7785. 